\begin{tabular}{|c|c|c|}
\hline \multirow{3}{*}{$\begin{array}{r}\text { Case Reports in } \\
\text { Gastroenterology }\end{array}$} & \multirow{2}{*}{\multicolumn{2}{|c|}{ Case Rep Gastroenterol 2016;10:749-754 }} \\
\hline & & \\
\hline & $\begin{array}{l}\text { DOI: } 10.1159 / 000452760 \\
\text { Publisnea onilne: December 13, } 2016\end{array}$ & $\begin{array}{l}\text { (c) } 2016 \text { The Author(s) } \\
\text { Published by S. Karger AG, Basel } \\
\text { www.karger.com/crg }\end{array}$ \\
\hline & $\begin{array}{l}\text { This article is licensed under the } \\
\text { International License (CC BY-NC) (h } \\
\text { Usage and distribution for commercial }\end{array}$ & $\begin{array}{l}\text { mons Attribution-NonCommercial } 4.0 \\
\text { ger.com/Services/OpenAccessLicense). } \\
\text { uires written permission. }\end{array}$ \\
\hline
\end{tabular}

\title{
Intrapancreatic Accessory Spleen: A Diagnosis Not to Forget!
}

\author{
Susana Marques $^{a} \quad$ Miguel Bispo $^{a} \quad$ Lariño Noia $^{b}$ \\ ${ }^{a}$ Department of Gastroenterology, Centro Hospitalar Lisboa Ocidental, Lisbon, Portugal; \\ ${ }^{b}$ Department of Gastroenterology, Hospital Clínico Universitario Santiago de Compostela, \\ Santiago de Compostela, Spain
}

\section{Keywords}

Endoscopic ultrasonography $\cdot$ Pancreas $\cdot$ Spleen

\begin{abstract}
A 69-year-old male patient was incidentally diagnosed with a 5-mm lesion in the pancreatic tail by endoscopic ultrasound (EUS). After contrast-enhanced EUS and EUS-elastography, all imaging features were highly suggestive of a benign pancreatic solid lesion such as an intrapancreatic accessory spleen (IPAS) or a benign neuroendocrine tumor. Interposition of the splenic artery precluded EUS-guided fine-needle aspiration (FNA). When an asymptomatic pancreatic mass is detected, IPAS diagnosis should be considered, and, if EUS-FNA is infeasible, contrast-enhanced EUS and EUS-elastography are useful tools to differentiate a pancreatic benign lesion as IPAS from a malignancy, with avoidance of unnecessary surgery.
\end{abstract}

(C) 2016 The Author(s)

Published by S. Karger AG, Basel

\section{Introduction}

The widespread use of noninvasive imaging techniques such as abdominal ultrasound (US), computed tomography, and magnetic resonance imaging has resulted in an increased identification of asymptomatic pancreatic lesions. Despite uncommon, a benign pancreatic lesion not to forget is an intrapancreatic accessory spleen (IPAS). 


\section{Case Presentation}

A 69-year-old male patient without known pancreatic disease was referred for endoscopic ultrasound (EUS) examination for suspected choledocholithiasis. Endosonographically, a 5-mm hypoechoic lesion was observed in the pancreatic tail. It was a round-shaped, well-defined, homogeneous pancreatic mass with identical echogenicity to the spleen (Fig. 1). The remaining pancreas was unremarkable. After the administration of sonographic contrast (SonoVue ${ }^{\circledR}$; Bracco, Milano, Italy), the lesion showed a uniform hyperenhancing appearance compared with the surrounding pancreas (Fig. 2). The lesion characterization was complemented by EUS-elastography, which displayed a homogeneous, green elastographic pattern (Fig. 3). These features together were highly suggestive of a benign pancreatic solid lesion such as an IPAS or a benign neuroendocrine tumor (NET). Interposition of the splenic artery between the probe and the lesion precluded EUS-guided fine-needle aspiration (FNA). Therefore, a definite pathological diagnosis was not possible to achieve, and the patient was scheduled for a second EUS within 6 months to re-evaluate the pancreatic lesion.

\section{Discussion}

Accessory spleen is a benign congenital anomaly in which there is failure of fusion between a portion of the splenic tissue and the main body of the spleen during embryologic splenic development [1]. It is a relatively common entity with an approximate prevalence of $10-30 \%$ [2-4]. The most frequent location is the splenic hilum (80\%), followed by the pancreatic tail (17\%) [5]. It is usually asymptomatic and incidentally diagnosed during imaging studies performed for other purposes [6]. As a benign condition, it does not require surgical treatment or follow-up. However, when located within the pancreas, it can mimic a pancreatic solid neoplasm. Thus, it is crucial to accurately differentiate IPAS from pancreatic neoplasms to avoid unnecessary surgery.

Different imaging modalities have been used to achieve IPAS diagnosis noninvasively, such as abdominal US, computed tomography, and magnetic resonance imaging. Radiologically, an IPAS tends to be a small, round, and homogeneous lesion with well-defined borders and is usually located within the pancreatic tail. Its hypervascular nature and imaging characteristics similar to the adjacent spleen may support the diagnosis [7]. Therefore, imaging studies should be contrast-enhanced and should parallel the spleen. IPAS differential diagnosis includes pancreatic hypervascular neoplasms such as pancreatic NET, metastases, solid pseudopapillary tumor, and adenocarcinoma [2, 6]. As a well-defined homogeneous and hypervascular lesion, it is most frequently misdiagnosed as a pancreatic NET. Octreotide scan has a high sensitivity (70-95\%) for the detection of gastrointestinal NET and can be useful in the differential diagnosis from this pancreatic neoplasm [8, 9]. However, falsepositive results have been reported in IPAS. This is due to the presence of somatostatin receptors in IPAS lymphocytes, which also have a high affinity to octreotide, therefore mimicking a pancreatic NET. Moreover, around $30-40 \%$ of the pancreatic NET are nonfunctioning and present normal hormone levels, further complicating the differential diagnosis from IPAS $[1,7]$. Other imaging modalities that have been proven to help identify IPAS include 99mTc-sulfur colloid scintigraphy and contrast-enhanced EUS [2]. There are very few studies characterizing EUS features of IPAS, and the largest published case series included only 11 patients [9]. IPAS is endosonographically described as a round-to-oval-shaped, small lesion, usually less than $2 \mathrm{~cm}$ in diameter, with well-defined margins, a homogeneous echotexture, 
and an echogenicity lower than the adjacent pancreas and identical to that of the spleen. The remaining pancreatic parenchyma and the pancreatic duct are normal. EUS Doppler mode may confirm its increased vascularity [2, 6]. As a hypervascular pancreatic lesion, using contrast-enhanced EUS, IPAS typically shows a marked and homogeneous hyperenhancing appearance during the arterial phase compared with the surrounding pancreatic parenchyma $[6,10]$.

Although newer imaging modalities have increased the likelihood of an accurate diagnosis of IPAS, they lack specificity. Consequently, many patients are still misdiagnosed as having a pancreatic neoplasm and undergo an unnecessary pancreatic resection [2, 7]. Indeed, about $1-5 \%$ of the pancreatectomies performed with the primary diagnosis of pancreatic carcinomas are later proved to be nonneoplastic, space-occupying lesions [11, 12]. Fortunately, this percentage is decreasing with the improved radiologic and endoscopic sampling diagnostic capabilities, in particular with EUS-FNA. EUS-FNA has been demonstrated to be a safe and effective tool to obtain a definitive IPAS diagnosis [1, 2, 7, 8-13]. In the largest study of IPAS diagnosis established using EUS-FNA, this technique was successful in $90 \%$ of the cases, and no complications were reported [9]. The cytologic features of the splenic tissue are characterized by small lymphocytes with a mixed inflammatory infiltrate with the appearance of the white pulp and presence of thin-walled blood vessels, which represent the splenic sinuses. When a cell block or histology is available, confirmation by CD8 immunohistochemical staining, a commonly used T-cell marker that is taken up by endothelial cells of the splenic sinus, is recommended [2, 7]. This stain is highly specific, since systemic endothelial cells and hemagioma are negative [1]. Moreover, a negative staining with chromogranin and low-molecular-weight cytokeratin rules against NET [7].

Nonetheless, sometimes EUS-FNA may be infeasible due to technical difficulties, such as interposed vascular structures, as in the case presented. In this setting, EUS qualitative and quantitative elastography may be useful tools to support IPAS diagnosis. It has been reported that benign pancreatic masses have increased elasticity compared to malignant ones, therefore displaying a green elastographic pattern $[14,15]$. In addition to EUS elastography, imaging follow-up may be appropriate when EUS-FNA is not possible to be performed.

\section{Conclusion}

In conclusion, when an asymptomatic pancreatic mass is detected, IPAS diagnosis should be considered, especially if the lesion has the same imaging features as the spleen. EUS-FNA should be performed to ensure the correct diagnosis and management, with avoidance of unnecessary surgery. When EUS-FNA is infeasible, contrast-enhanced EUS and EUSelastography are useful tools in the differential diagnosis between a pancreatic benign lesion such as IPAS and a pancreatic malignancy.

\section{Statement of Ethics}

There are no ethical conflicts to declare. 


\section{Case Reports in \\ Gastroenterology}

Marques et al.: Intrapancreatic Accessory Spleen: A Diagnosis Not to Forget!

\section{Disclosure Statement}

The authors have no conflicts of interest to disclose.

\section{References}

-1 Saunders TA, Miller TR, Khanafshar E: Intrapancreatic accessory spleen: utilization of fine needle aspiration for diagnosis of a potential mimic of a pancreatic neoplasm. J Gastrointest Oncol 2016;7(suppl 1):S62-S65.

2 Krishna SG, Heif MM, Sharma SG, Pandey T, Rego RF: Intrapancreatic accessory spleen: investigative dilemmas and role of EUS-guided FNA for diagnostic confirmation. JOP 2011;12:603-606.

-3 Guo W, Han W, Lin J, et al: Intrapancreatic accessory spleen: a case report and review of literature. World J Gastroenterol 2009;15:1141-1143.

4 Schreinier AM, Mansoor A, Faigel DO, Morgan TK: Intrapancreatic accessory spleen: mimic of pancreatic tumor diagnosed by endoscopic ultrasound guided fine needle aspiration biopsy. Diagn Cytopathol 2008;36:262-265.

5 Halpert B, Gyorkey F: Lesions observed in accessory spleens of 3,011 patients. Am J Clin Pathol 1959;32:165-168.

-6 De Robertis R, D’Onofio M, Manfrin E, et al: A rare case of pancreatic head splenosis diagnosed by contrast-enhanced ultrasound. Ultraschall Med 2014;35:72-74.

7 Okun SD, Lewin DN: Non-neoplastic pancreatic lesions that may mimic malignancy. Semin Diagn Pathol 2015;33:31-42.

8 Toussaint E, Flamen P, Demetter P, Matos C, Van Gossum M, Delhaye M, et al: A rare case of a pancreatic mass due to accessory spleen; when EUS-FNA is not enough. Endoscopy 2011;43(suppl)UCTN:E221E222.

-9 Ardengh C, Lopes V, Kemp R, Lima-Filho ER, Venco F: Pancreatic splenosis mimicking neuroendocrine tumors: endoscopic ultrasound guided fine needle aspiration. Arq Gastroenterol 2013;50:10-14.

10 Will U, Arciadacono P, Petrone MC, et al: Differential diagnosis of small solid pancreatic lesions. Gastrointest Endosc 2016;84:933-940

11 Adsay NV, Basturk O, Lnimstra DS, Kloppel G: Pancreatic pseudotumors: non-neoplastic solid lesions of the pancreas that clinically mimic pancreas cancer. Semin Diagn Pathol 2004;21:260-267.

12 Wick MR, Tazelaar HD: Pseudoneoplastic lesions: general conditions. Arch Pathol Lab Med 2010;134:351-361.

13 Bastidas AB, Holloman D, Lankarani A, Jose M: Endoscopic ultrasound-guided needle-based probe confocal laser endomicroscopy (nCLE) of intrapancreatic ectopic spleen. ACG Case Rep J 2016;3:196198.

14 Iglesias-Garcia J, Larino-Noia J, Abdulkader I, Forteza J: EUS elastography for the characterization of solid pancreatic masses. Gastrointest Endosc 2009;70:1101-1108.

$\checkmark 15$ Iglesias-Garcia J, Larino-Noia J, Abdulkader I, Forteza J, Munoz JED: Quantitative endoscopic ultrasound elastography: an accurate method for the differentiation of solid pancreatic masses. Gastroenterology 2010;139:1172-1180. 


\section{Case Reports in Gastroenterology

\begin{tabular}{|c|c|}
\hline \multicolumn{2}{|c|}{ Case Rep Gastroenterol 2016;10:749-754 } \\
\hline DOI: $10.1159 / 000452760$ & $\begin{array}{l}\text { (c) } 2016 \text { The Author(s). Published by S. Karger AG, Basel } \\
\text { www.karger.com/crg }\end{array}$ \\
\hline
\end{tabular} \\ Marques et al.: Intrapancreatic Accessory Spleen: A Diagnosis Not to Forget!}

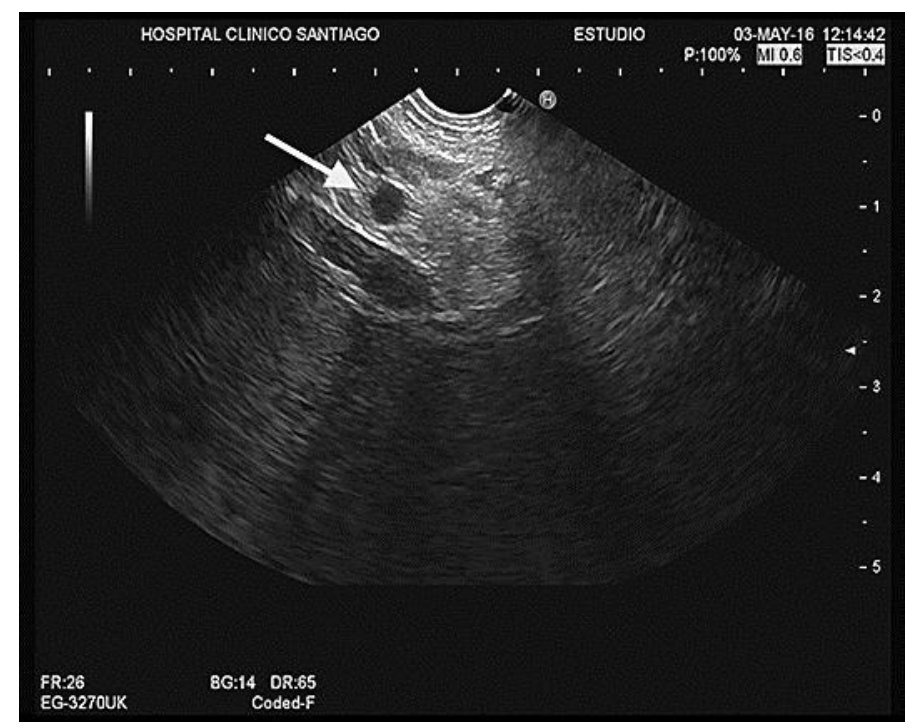

Fig. 1. Endoscopic ultrasound (transgastric view). A round-shaped, well-defined, homogeneous, hypoechoic lesion was observed in the pancreatic tail (between the splenic artery and the splenic vein).

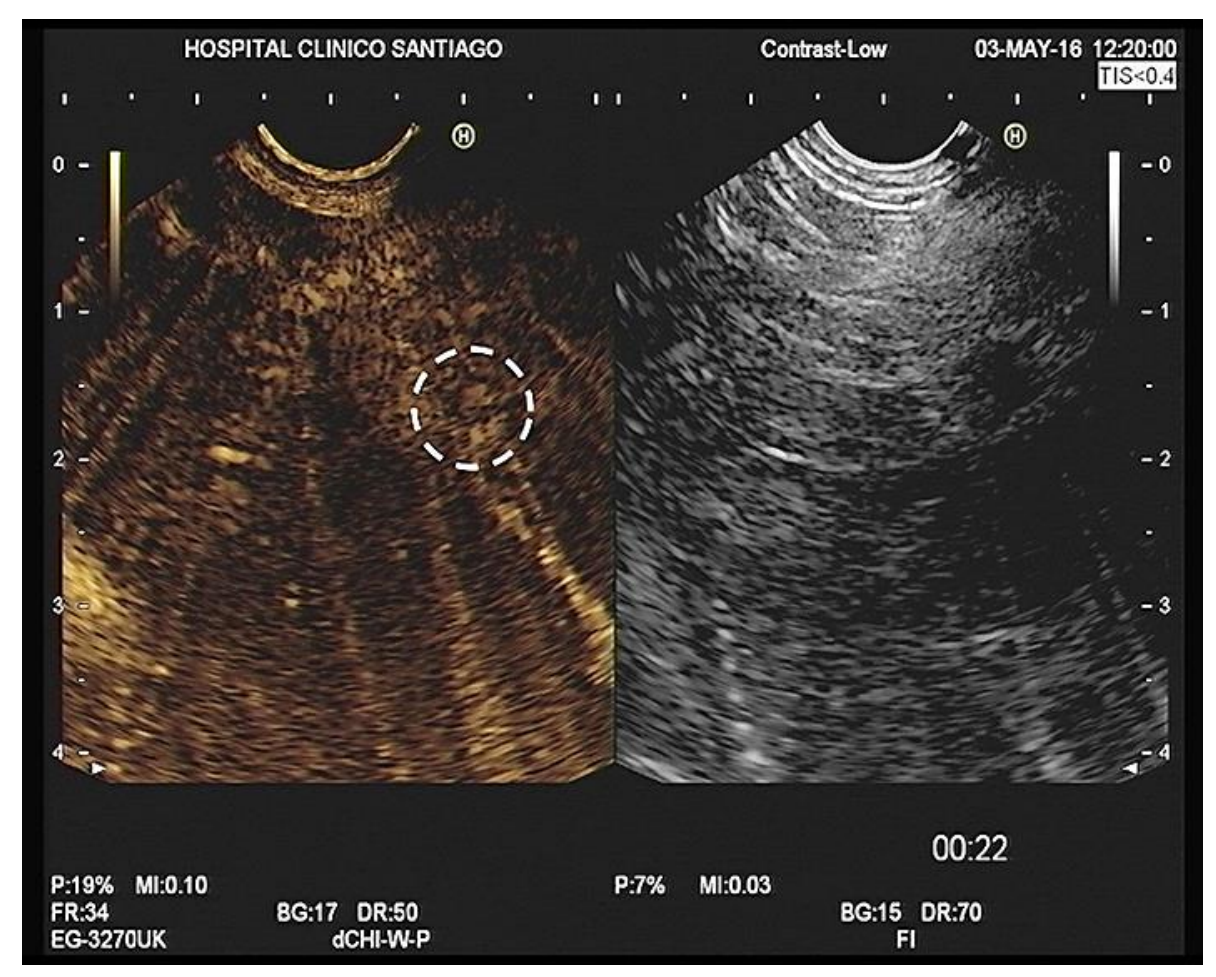

Fig. 2. Contrast-enhanced endoscopic ultrasound (transgastric view). The lesion showed a uniform, hyperenhancing appearance compared with the surrounding pancreas. 


\begin{tabular}{|c|c|c|}
\hline \multirow{3}{*}{$\begin{array}{r}\text { Case Reports in } \\
\text { Gastroenterology }\end{array}$} & \multirow{2}{*}{\multicolumn{2}{|c|}{ Case Rep Gastroenterol 2016;10:749-754 }} \\
\hline & & \\
\hline & DOI: $10.1159 / 000452760$ & $\begin{array}{l}\text { (c) } 2016 \text { The Author(s). Published by S. Karger AG, Basel } \\
\text { www.karger.com/crg }\end{array}$ \\
\hline
\end{tabular}

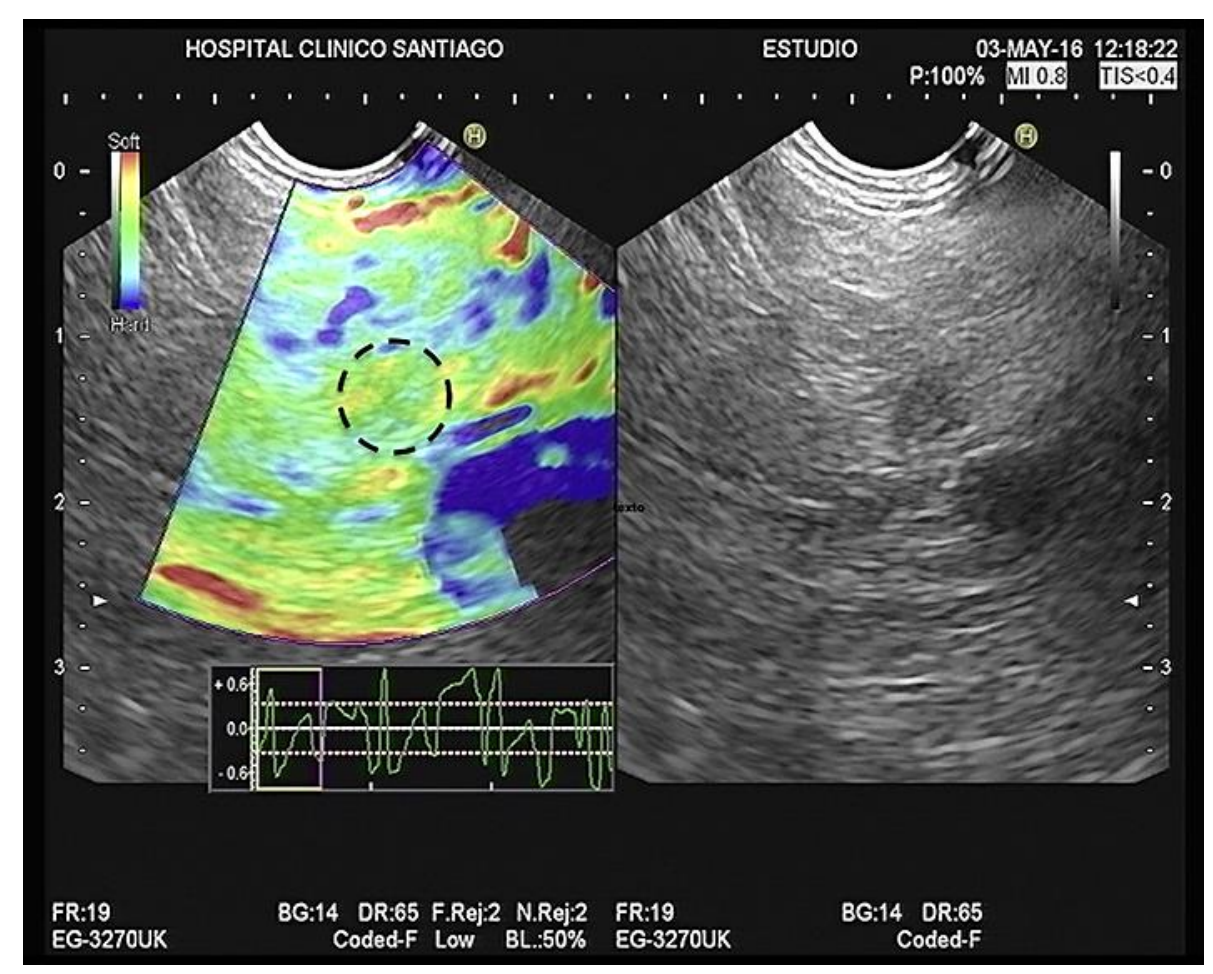

Fig. 3. Endoscopic ultrasound elastography (transgastric view). The lesion displayed a homogeneous, green elastographic pattern. 